\title{
Prognostic Impact of a Nutritional Index Including Muscle Volume in Stage 4 Colorectal Cancer
}

\author{
TOMOYUKI NAGATA, YUEN NAKASE, KEI NAKAMURA, AKIRA SOUGAWA, \\ SATOSHI MOCHIDUKI, SHOZO KITAI and SEISHIRO INABA \\ Department of Surgery, Nara City Hospital, Nara, Japan
}

\begin{abstract}
Background: Nutritional status influences cancer prognosis. Measurement of the area of the psoas muscle on computed tomography is useful for evaluation of skeletal muscle mass and prediction of prognosis. Patients and Methods: The psoas muscle index (PMI) was determined in 42 patients undergoing surgery for stage 4 colorectal cancer. Patients were classified into high and low PMI groups using a cutoff of $5.5 \times 10^{-4} \mathrm{~cm}^{2} \mathrm{~m}^{-2}$. Relationships of PMI with prognosis, chemotherapy period, and postoperative complications were examined. Results: The 3-year overall survival rate was $24.0 \%$. PMI was significantly associated with 3-year OS in univariate (high vs. low PMI: $43.0 \%$ vs. $12.9 \%, p=0.0415)$ and multivariate $(p=0.0146)$ analyses. $A$ low PMI was associated with a shorter period of chemotherapy. A reduction in PMI was a predictor of a poor prognosis. Conclusion: PMI status is related to the period of chemotherapy and is an independent prognostic factor in patients with stage 4 colorectal cancer.
\end{abstract}

Nutritional status influences the prognosis of advanced cancer (1). Many studies have examined prediction of preoperative nutritional status using data from blood tests (2). However, these values are likely to be modified by preoperative therapies such as antibiotics or replacement therapy. Skeletal muscle volume may also be a useful index for predicting the prognosis of patients with advanced cancer because many such patients have involuntary loss of skeletal muscle (3). The psoas muscle mass assessed by computed tomography (CT) may also be a predictor of prognosis (4). A reduction of this mass has recently been associated with treatment toxicity

Correspondence to: Tomoyuki Nagata, Ph.D., Department of Surgery, Nara City Hospital, 1-50-1 Higashikidera-cho, Nara-city, Nara 630-8305, Japan. Tel: +81 0742241251, Fax: +81 0742222478, e-mail: drgechum@koto.kpu-m.ac.jp

Key Words: Psoas muscle, stage 4 colorectal cancer, nutritional index. and poor functional status in patients with cancer $(5,6)$, and loss of muscle mass has been found to aggravate the prognosis of pancreatic and hepatic cancer $(4,7)$.

In this study, we investigated the impact of the crosssectional area of the psoas muscle measured on CT on the prognosis of patients with stage 4 colorectal cancer at our hospital, and we compared this area with other nutritional indices and clinicopathological factors.

\section{Patients and Methods}

Patient population and data collection. The participants were 42 patients with stage 4 colorectal cancer who underwent surgery at our Department between April 2010 and March 2015. The patients were followed-up until death or the final date of observation (March $31,2016)$ by outpatient clinic consultation, and communication via telephone or letter. The median and mean follow-up periods were 348 and 406 days (range $=8-1,760$ days), respectively. A study of clinicopathological factors including preoperative nutritional evaluation was performed retrospectively.

Nutritional indices. Three preoperative nutritional indices were examined: (i) body mass index (BMI), calculated as body weight $(\mathrm{kg}) /(\text { body height }(\mathrm{m}))^{2}$; (ii) nutritional data from blood tests, including (a) albumin level and lymphocyte number; (b) the prognostic nutritional index $(\mathrm{PNI})$, calculated as $10 \times$ albumin $(\mathrm{g} / \mathrm{dl})$ $+0.005 \times$ lymphocyte number; and (c) the control of nutritional status (CONUT) score, calculated from albumin, lymphocyte number and total cholesterol (Table I) and grouped into grades for nutritional disorder from normal to severe (8); and (iii) the psoas muscle index (PMI), calculated as the sum of bilateral psoas muscle cross-sectional areas $\left(\mathrm{cm}^{2}\right) /[\text { body height }(\mathrm{m})]^{2}$.

Skeletal muscle volume was assessed using PMI before surgery, with PMI $\geq 5.5 \times 10^{-4}$ and $<5.5 \times 10^{-4} \mathrm{~cm}^{2} \mathrm{~m}^{-2}$ defined as high and low, respectively. The factor of $10^{-4}$ is omitted in the PMI values described below. Relationships between PMI status and other clinicopathological factors were examined, and the prognostic impact of PMI was evaluated in univariate and multivariate analysis. The association of PMI with complications was examined by comparing the incidences of complications and surgical site infection (SSI) in the high and low PMI groups. Major complications were defined as grade 1 or more in the Clavien-Dindo classification (9). The relationship between PMI and chemotherapy 
Table I. Control of nutritional status (CONUT) scores, calculated from the sum of scores for albumin, lymphocyte number and total cholesterol and grouped into grades of nutritional status from normal to severe (11).

\begin{tabular}{|c|c|c|c|c|}
\hline \multicolumn{5}{|c|}{ CONUT } \\
\hline Albumin (g/dl) & $\geq 3.50$ & $3.00-3.49$ & $2.50-2.99$ & $<2.50$ \\
\hline Score (A) & 0 & 2 & 4 & 6 \\
\hline Lymphocyte number & $\geq 1600$ & $1200-1599$ & 800-1199 & $<800$ \\
\hline Score $(B)$ & 0 & 1 & 2 & 3 \\
\hline Total cholesterol (mg/dl) & $\geq 180$ & $140-179$ & $100-139$ & $<100$ \\
\hline Score $(\mathrm{C})$ & 0 & 1 & 2 & 3 \\
\hline \multicolumn{5}{|c|}{ Grade } \\
\hline$(\mathrm{A})+(\mathrm{B})+(\mathrm{C})$ & $0-1$ & $2-4$ & $5-8$ & $>8$ \\
\hline Nutritional status & Normal & Mild disorder & Moderate disorder & Severe disorder \\
\hline
\end{tabular}

period was also analyzed. The impact of changes in PMI on prognosis was evaluated by classifying patients into groups with cut-offs at 5-point intervals.

Image analysis. CT scans for planning of surgery were used for measuring the cross-sectional area of the psoas muscles at the inferior border of the third lumbar vertebra (L3) (Figure 1). Skeletal muscle depletion is normally assessed by measuring the psoas muscle at L3 because skeletal muscle and adipose tissue areas at L3 are significantly related to whole-body tissue mass in healthy adults (10) and cancer patients (11). Muscle cross-sectional area was computed by summing tissue pixels and multiplying by the pixel surface area. Surface areas were normalized for stature $\left(\mathrm{m}^{2}\right)$ and are reported as the PMI $\left(\mathrm{cm}^{2} \mathrm{~m}^{-2}\right)(10-12)$.

Statistical analysis. Statistical analysis and graphing were performed with JMP 7.0.1 (SAS Institute Inc., Tokyo, Japan). Continuous data are expressed as the median or mean, depending on the data distributions. A Chi-square test and $t$-test (or Fisher test) were used for univariate comparisons. Overall survival (OS) rates were calculated by the Kaplan-Meier method, starting from the date of surgery. Chemotherapy periods were also calculated by the KaplanMeier method starting from the date of first chemotherapy. Differences in OS were examined by log-rank test. Multivariate analysis of prognostic factors related to OS was performed using a Cox proportional hazard model with variables that were significant prognostic factors in univariate analysis. In all analyses, a value of $p<0.05$ was considered to indicate significance.

\section{Results}

The median OS was 11.6 months, and the 3- and 5-year OS rates were $24.0 \%$ and $12.1 \%$, respectively. Factors indicating stage 4 cancer and their distribution are listed in Table II. The PMI range was 2.47-10.46 and the mean was 5.55 \pm 1.89 .

Clinicopathological features of patients with high and low PMI are listed in Table III. There were significant differences in age, gender, albumin level, PNI, and CONUT score between these groups, but not in BMI or other factors.
In univariate analysis, PMI was a significant factor associated with 3-year OS (high vs. low: $43.0 \%$ vs. $12.9 \%$, $p=0.0415$ ). Furthermore there were significant differences in 3-year OS in regard to ascites, BMI, lymphocyte count, CONUT score, pathological $\mathrm{P}$ status, resection of the primary tumor, postoperative metastatic site, chemotherapy and molecular targeted therapy. In multivariate analysis, PMI, resection of the primary tumor and chemotherapy were independent prognostic factors for 3-year OS (Table IV).

Resection of the primary tumor was performed in 32 out of the 42 patients. There was no significant difference in PMI status, incidence of complications using the ClavienDindo classification, or incidence of SSI after resection of the primary tumor (Figure 2).

Postoperative chemotherapy was performed in 27 patients and intensive follow-up was conducted in 15 patients. The mean chemotherapy period was 384 days (range $=35-1706$ days). Two of the patients underwent irradiation therapy for an unresectable primary rectal tumor and lateral lymph nodes. Our postoperative chemotherapy regimens consisted of oxaliplatin/5-FU/leucovorin (FOLFOX) with/without molecular targeted therapy $(n=18)$, capecitabine/ oxaliplatin (CapeOX) \pm molecular targeted therapy $(n=4)$, TS-1(Tegafur/ Gimeracil/Oteracil)/ oxaliplatin (SOX) $(n=1)$, irinotecan/TS1(Tegafur/Gimeracil/Oteracil) (IRIS) $(n=1)$ amongst others. No patients received neoadjuvant chemotherapy. The high PMI group had a significantly longer chemotherapy period compared to the low PMI group (Figure 3).

CT was performed twice or more in 25 patients. The median rate of change in PMI was $-4.14 \times 10^{-2}$ month $^{-1}$ in these patients. Many patients with stage 4 cancer lose their body muscle volume. Relationships of prognosis with PMI below and above a series of cut-offs separated by 5 points are shown in Figure 4. For negative cut-offs, there were significant differences in prognosis for PMIs that were lower and higher than each cut-off $(p<0.0001$ to $p=0.0013)$. 


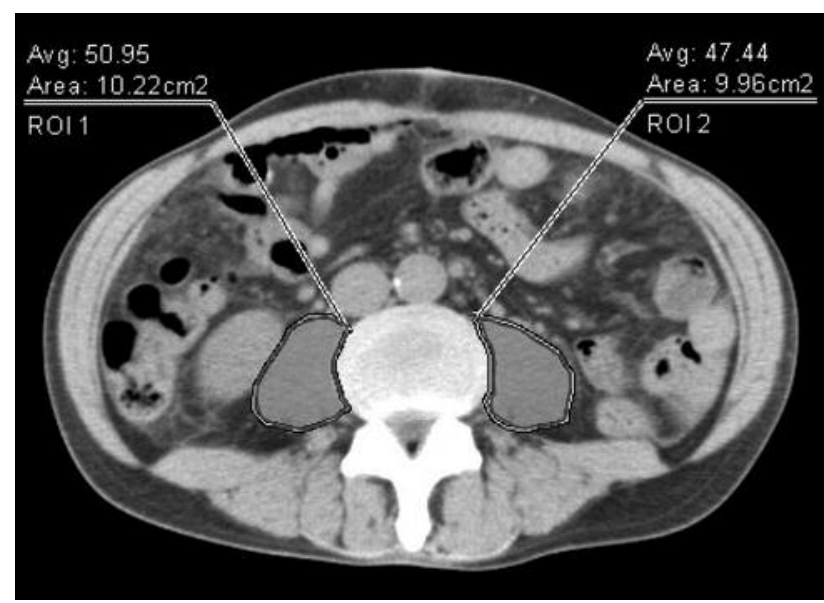

Figure 1. Psoas muscle cross-sectional areas measured in computed tomographic images at the inferior border of the third lumbar vertebra. ROI 1; Right psoas muscle: ROI 2; left psoas muscle.

Table II. Factors defining stage 4 cancer.

\begin{tabular}{lc}
\hline Factor & No. of patients \\
\hline Liver metastasis & 29 \\
Lung metastasis & 9 \\
Peritoneum metastasis & 16 \\
Distant lymph node metastasis & 9 \\
Bone metastasis & 1 \\
\hline Multiple factors & 15
\end{tabular}

\section{Discussion}

The cumulative 5-year OS for patients with stage 4 colon cancer is $13.2 \%$ based on data from the Japanese Society for Cancer of the Colon and Rectum (13), and this rate increases to $30-60 \%$ in the subgroup who undergo curative surgery $(14,15)$. In the present study, primary tumor resection was identified as an independent prognostic factor in stage 4 colon cancer.

Advanced cancer produces metabolic abnormalities in skeletal muscle and adipose tissue and patients expend a large amount of energy (1). This persistent hypermetabolic state accelerates decomposition of muscle and adipose tissue, which results in loss of body weight. Bozzetti showed that the lost body weight in patients with advanced cancer is correlated with their base energy expenditure under resting conditions (16). Wu et al. also found that patients with esophageal cancer who were losing body weight had greater energy expenditure under resting conditions compared to
Table III. Clinicopathological features of patients with high and low psoas muscle index (PMI). PMI $\geq 5.5 \times 10^{-4}$ and $<5.5 \times 10^{-4} \mathrm{~cm}^{2} \mathrm{~m}^{-2}$ defined as high and low, respectively.

\begin{tabular}{|c|c|c|c|}
\hline & $\begin{array}{l}\text { High PMI } \\
\quad(\mathrm{n}=15)\end{array}$ & $\begin{array}{c}\text { Low PMI } \\
(\mathrm{n}=27)\end{array}$ & $p$-Value \\
\hline Age (years) & $56.6 \pm 3.0$ & $71.9 \pm 2.3$ & 0.0002 \\
\hline \multicolumn{4}{|l|}{ Gender } \\
\hline Female & 3 & 17 & \multirow[t]{2}{*}{0.0107} \\
\hline Male & 12 & 10 & \\
\hline \multicolumn{4}{|l|}{ Pre-CT ascites } \\
\hline Present & 7 & 15 & \multirow[t]{2}{*}{0.7488} \\
\hline Absent & 8 & 12 & \\
\hline Body mass index $\left(\mathrm{kg} / \mathrm{m}^{2}\right)$ & $21.5 \pm 0.76$ & $20.7 \pm 0.57$ & 0.3839 \\
\hline Albumin $(\mathrm{g} / \mathrm{dl})$ & $3.9 \pm 0.16$ & $3.1 \pm 0.12$ & 0.0004 \\
\hline Lymphocyte number/ $\mu$ l & $1483 \pm 135$ & $1291 \pm 101$ & 0.2599 \\
\hline PNI & $46.42 \pm 1.84$ & $37.90 \pm 1.37$ & 0.0006 \\
\hline CONUT & $1.8 \pm 0.85$ & $4.10 \pm 0.64$ & 0.0414 \\
\hline Tumor major size $(\mathrm{mm})$ & $46.0 \pm 6.8$ & $59.5 \pm 4.9$ & 0.1183 \\
\hline \multicolumn{4}{|l|}{ Tumor location } \\
\hline Rectum & 8 & 7 & \multirow[t]{2}{*}{0.1002} \\
\hline Other & 7 & 20 & \\
\hline \multicolumn{4}{|l|}{$\mathrm{T}$} \\
\hline $\mathrm{T} 4 \mathrm{~b}$ & 4 & 8 & \multirow[t]{2}{*}{1.0000} \\
\hline Other & 11 & 19 & \\
\hline \multicolumn{4}{|l|}{$\mathrm{N}$} \\
\hline N0-1 & $0-11$ & $0-15$ & \multirow[t]{2}{*}{0.3878} \\
\hline $\mathrm{N} 2-3$ & $2-314$ & $2-321$ & \\
\hline \multicolumn{4}{|l|}{$\mathrm{H}$} \\
\hline Present & 11 & 18 & \multirow[t]{2}{*}{0.7387} \\
\hline Absent & 4 & 9 & \\
\hline \multicolumn{4}{|l|}{$\mathrm{LM}$} \\
\hline Present & 3 & 6 & \multirow[t]{2}{*}{1.0000} \\
\hline Absent & 12 & 21 & \\
\hline \multicolumn{4}{|l|}{$\mathrm{P}$} \\
\hline Present & 7 & 9 & \\
\hline Absent & 8 & 18 & 0.5113 \\
\hline \multicolumn{4}{|l|}{ Distant LN metastasis } \\
\hline Present & 5 & 4 & \multirow[t]{2}{*}{0.2417} \\
\hline Absent & 10 & 23 & \\
\hline \multicolumn{4}{|l|}{ Primary tumor } \\
\hline Resected & 13 & 19 & \multirow[t]{2}{*}{0.2860} \\
\hline Residual & 2 & 8 & \\
\hline Operative time (min) & $197 \pm 29$ & $206 \pm 22$ & 0.7929 \\
\hline Blood loss (g) & $238.2 \pm 87.6$ & $223.3 \pm 65.3$ & 0.8922 \\
\hline \multicolumn{4}{|l|}{ Histological type } \\
\hline Well/mod. & 12 & 22 & \multirow[t]{2}{*}{0.2802} \\
\hline Poor & 3 & 1 & \\
\hline
\end{tabular}

Pre-CT ascites: Ascites on preoperative computed tomography; PNI: prognostic nutritional index; CONUT: Control of nutritional status; $\mathrm{T}$ : pathological T grade; N: pathological $\mathrm{N}$ grade; $\mathrm{H}$ : clinical/surgical $\mathrm{H}$ grade; LM: clinical/surgical LM grade; P: pathological/surgical $\mathrm{P}$ grade; Well: well-differentiated; mod.: moderately differentiated; Poor: poorly differentiated. Data are the mean \pm SD or the number of patients. Significantly different data are shown in bold.

healthy individuals (17). Thus, malnutrition in advanced cancer results in loss of body weight. The process in which the hypermetabolic state accelerates decomposition is 
Table IV. Prognostic impact of psoas muscle index (PMI) status evaluated by univariate and multivariate analyses.

\begin{tabular}{|c|c|c|c|c|c|c|}
\hline & \multirow[b]{2}{*}{ Subgroup } & \multirow[b]{2}{*}{ No.pts } & \multirow[b]{2}{*}{3 -YSR $(\%)$} & \multirow{2}{*}{$\frac{\text { Univariate analysis }}{p \text {-Value }}$} & \multicolumn{2}{|c|}{ Multivariate analysis } \\
\hline & & & & & $p$-Value & $\mathrm{RR}^{*}$ \\
\hline \multirow[t]{2}{*}{ Age } & $\geq 65$ Years & 22 & 15.9 & 0.1903 & & \\
\hline & $<65$ Years & 20 & 32.7 & & & \\
\hline \multirow[t]{2}{*}{ Gender } & Male & 22 & 22.9 & 0.9949 & & \\
\hline & Female & 20 & 25.5 & & & \\
\hline \multirow[t]{2}{*}{ Pre-CT ascites } & Present & 20 & 11.5 & 0.0263 & 0.2082 & 3.38 \\
\hline & Absent & 22 & 41.6 & & & \\
\hline \multirow[t]{2}{*}{ Body mass index } & $\geq 20 \mathrm{~kg} / \mathrm{m}^{2}$ & 27 & 35.1 & 0.0208 & 0.1644 & 0.39 \\
\hline & $<20 \mathrm{~kg} / \mathrm{m}^{2}$ & 15 & 6.1 & & & \\
\hline \multirow[t]{2}{*}{ Albumin } & $\geq 3.0 \mathrm{~g} / \mathrm{dl}$ & 31 & 29.1 & 0.1753 & & \\
\hline & $<3.0 \mathrm{~g} / \mathrm{dl}$ & 11 & 8.8 & & & \\
\hline \multirow[t]{2}{*}{ Lymphocyte number } & $\geq 800 / \mu \mathrm{l}$ & 35 & 27.5 & 0.0101 & 0.991 & 0.98 \\
\hline & $<800 / \mu \mathrm{l}$ & 7 & 1.2 & & & \\
\hline \multirow{2}{*}{ PNI } & $\geq 45$ & 15 & 48.9 & 0.0161 & 0.8939 & 0.89 \\
\hline & $<45$ & 27 & 11.0 & & & \\
\hline \multirow[t]{2}{*}{ CONUT } & $\geq 5$ & 9 & 4.5 & 0.0387 & 0.7965 & 1.23 \\
\hline & $<5$ & 24 & 34.5 & & & \\
\hline \multirow[t]{2}{*}{ PMI } & $\geq 5.5 \times 10^{-4}$ & 15 & 43.0 & 0.0415 & 0.0146 & 0.10 \\
\hline & $<5.5 \times 10^{-4}$ & 27 & 12.9 & & & \\
\hline \multirow[t]{2}{*}{ Tumor size } & $\geq 50 \mathrm{~mm}$ & 23 & 9.8 & 0.6086 & & \\
\hline & $<50 \mathrm{~mm}$ & 18 & 16.2 & & & \\
\hline \multirow[t]{2}{*}{ Tumor location } & Rectum & 16 & 8.8 & 0.9387 & & \\
\hline & Other & 27 & 12.6 & & & \\
\hline \multirow[t]{2}{*}{$\mathrm{T}$} & $\mathrm{T} 4 \mathrm{~b}$ & 12 & 6.3 & 0.2592 & & \\
\hline & other & 30 & 13.6 & & & \\
\hline \multirow[t]{2}{*}{$\mathrm{N}$} & N0-1 & 6 & 20.7 & 0.5298 & & \\
\hline & $\mathrm{N} 2-3$ & 35 & 10.9 & & & \\
\hline \multirow[t]{2}{*}{$\mathrm{H}$} & Present & 29 & 8.4 & 0.6213 & & \\
\hline & Absent & 13 & 17.8 & & & \\
\hline \multirow[t]{2}{*}{ LM } & Present & 9 & 11.4 & 0.9605 & & \\
\hline & Absent & 33 & 11.3 & & & \\
\hline \multirow[t]{2}{*}{$\mathrm{P}$} & Present & 16 & 9.0 & 0.0102 & 0.2019 & 2.64 \\
\hline & Absent & 26 & 37.4 & & & \\
\hline Distant LN metastasis & Present & 9 & 18.6 & 0.4000 & & \\
\hline & Absent & 33 & 9.4 & & & \\
\hline Primary tumor & Resected & 32 & 19.5 & 0.0002 & 0.0192 & 0.13 \\
\hline & Residual & 10 & 0.06 & & & \\
\hline Operative time & $\geq 150 \mathrm{~min}$ & 27 & 35.2 & 0.0501 & & \\
\hline & $<150$ min & 15 & 8.6 & & & \\
\hline Blood loss & $\geq 100 \mathrm{~g}$ & 18 & 21.0 & 0.2030 & & \\
\hline & $<100 \mathrm{~g}$ & 24 & 5.4 & & & \\
\hline Histological type & Well/mod. & 34 & 12.6 & 0.6405 & & \\
\hline & Poor & 4 & 7.4 & & & \\
\hline Postoperative metastasis site & $0-1$ & 16 & 31.9 & 0.0073 & 0.8948 & 0.90 \\
\hline & $2-4$ & 26 & 1.6 & & & \\
\hline Chemotherapy & Present & 27 & 18.4 & $<0.0001$ & 0.0285 & 0.02 \\
\hline & Absent & 15 & 0.0 & & & \\
\hline Molecularly-targeted therapy & Present & 23 & 17.6 & 0.0325 & 0.1889 & 0.16 \\
\hline & Absent & 18 & 2.3 & & & \\
\hline
\end{tabular}

3-YSR: 3-Year overall survival rate; RR: relative risk; pre-CT ascites: ascites in preoperative computed tomography; PNI: prognostic nutritional index; CONUT: Control of nutritional status; T: pathological T grade; $\mathrm{N}$ : pathological $\mathrm{N}$ grade; $\mathrm{H}$ : clinical/surgical $\mathrm{H}$ grade; LM: clinical/surgical LM grade; P: pathological/surgical P grade; LN: lymph node; Significant data are shown in bold. *First subgroup vs. second.

referred to as cancerous cachexia syndrome, and is characterized by changes in inflammation and other mediators that cause weight loss (18).
Sarcopenia is defined as a malnutritional status in skeletal muscle. Sarcopenia in cancer has been found to be a prognostic factor (19) that influences performance status, 

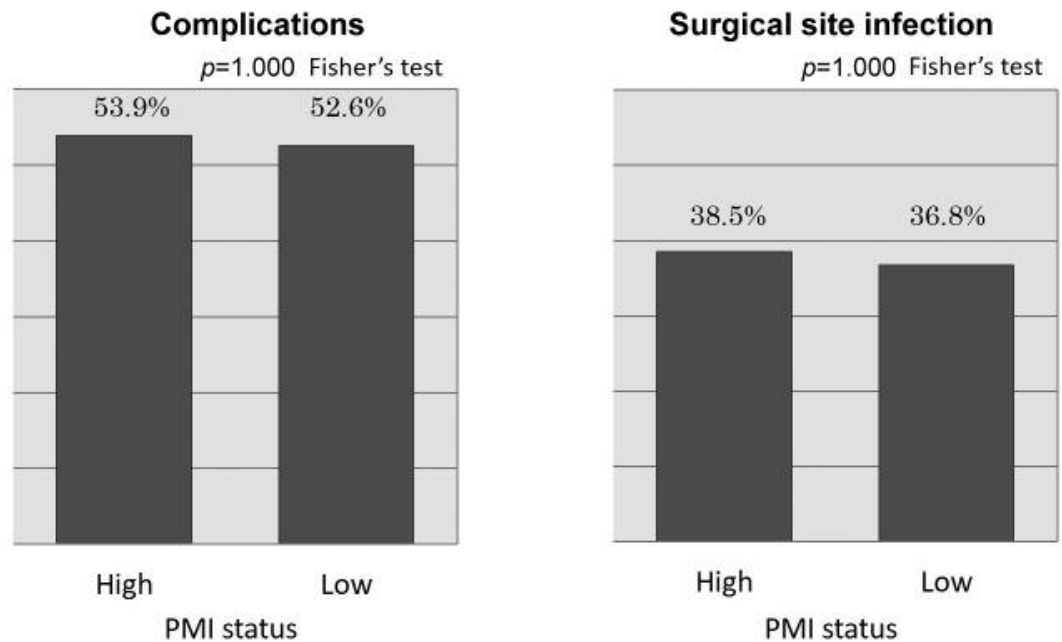

Figure 2. Psoas muscle index (PMI) status showed no significant relationship with the incidence of complications or surgical site infection. PMI $\geq 5.5 \times 10^{-4}$ and $<5.5 \times 10^{-4} \mathrm{~cm}^{2} \mathrm{~m}^{-2}$ defined as high and low, respectively.

quality of life and compliance with combined modality therapy such as chemoradiotherapy $(7,20-22)$. Depletion of muscle volume aggravates the prognosis of pancreatic and hepatic cancer. Thus, Otsuji et al. showed that preoperative sarcopenia increases morbidity, including liver failure, in patients who underwent major hepatectomy with extrahepatic bile duct resection (7), and Kataoka et al. found that patients with recurrence after pancreaticoduodenectomy had a significant loss of psoas muscle volume, reflecting their malnutritional state (4).

The results of univariate analysis of prognosis in the current study were consistent with these findings. The albumin level and lymphocyte count in blood tests do not necessarily correspond to the nutritional status of the patient, and measurement of muscle volume in CT or MRI may be superior in terms of objectivity and accuracy (2). Muscle depletion is hidden from view by a mantle of adipose tissue and there is a tendency to be unaware of the decline of muscle mass without use of imaging. Therefore, we investigated the impact of the psoas muscle cross-sectional area measured on $\mathrm{CT}$ on prognosis, complications and compliance with postoperative chemotherapy. In multivariate analysis, the muscle volume had a greater influence on the prognosis of stage 4 colorectal cancer compared to other nutritional indices calculated using data from blood tests. CT images are used for cancer staging and planning of surgery, and thus are a convenient resource for detection of skeletal muscle depletion. These images are routinely available in clinical records, and thus no additional stress is placed on the patient for assessment of nutritional status.

It is important to identify patients at greatest risk for postoperative complications, and depletion of muscle mass

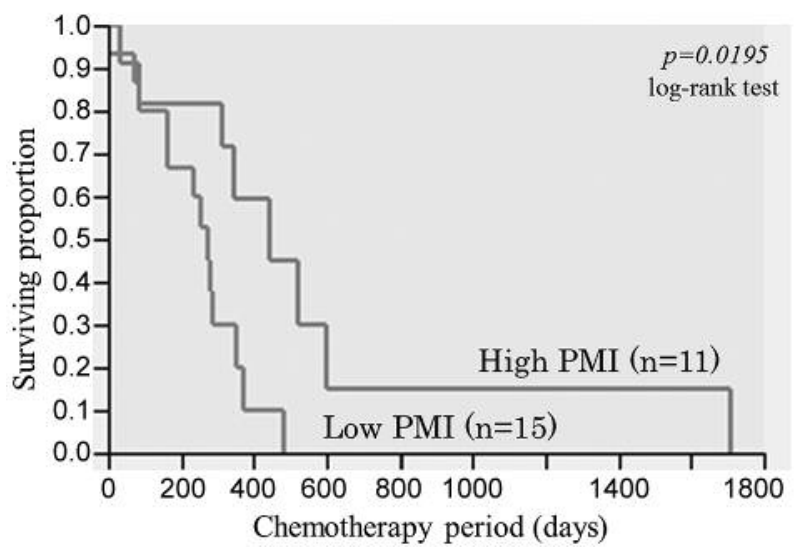

Figure 3. The high psoas muscle index (PMI) group had a significantly longer chemotherapy period compared with the low PMI group. PMI $\geq 5.5 \times 10^{-4}$ and $<5.5 \times 10^{-4} \mathrm{~cm}^{2} \mathrm{~m}^{-2}$ defined as high and low, respectively.

may indicate a high risk for these complications. Joglekar et $a l$. found that skeletal muscle depletion is a significant predictor of operative complications following pancreatectomy (22). Postoperative complications can lead to prolonged hospital stays and greater medical costs (23), and the psoas muscle volume may be a useful index of frailty and physiological capacity that might help predict the risk of complications. However, in this study, we did not find any association between skeletal muscle depletion and the incidence of complications. However, the participants were patients with stage 4 colorectal cancer who may have altered immunological and metabolic characteristics that prevented 


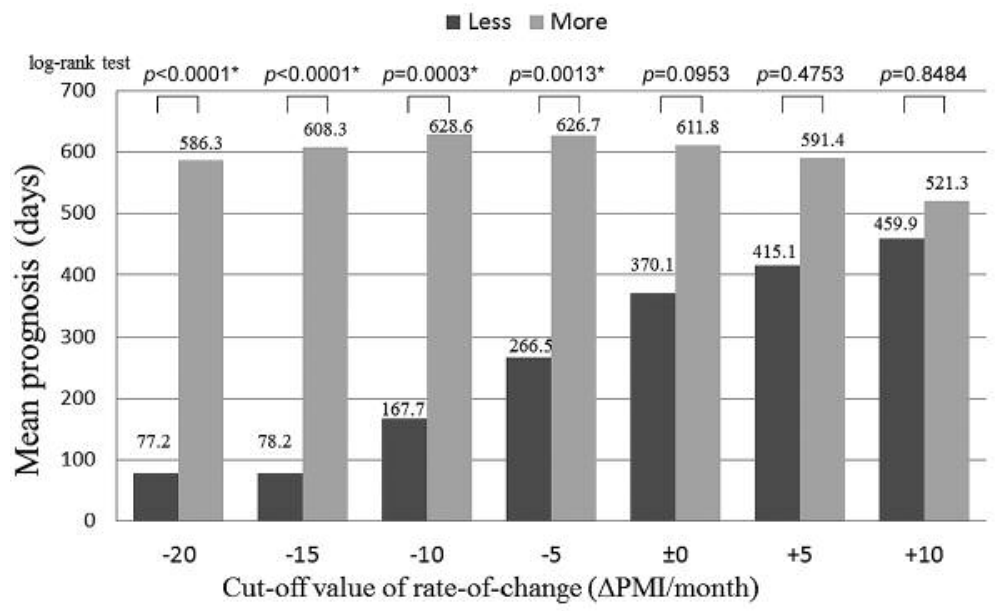

Figure 4. The rate of change of psoas muscle index (PMI) was related to prognosis. Cut-offs with negative values lead to significant differences in prognosis between groups with greater and smaller rates of PMI change. Less; The rate of PMI change in this group was smaller than the cut-off value. More; The rate of PMI change in this group was larger than the cut-off value.

identification of skeletal muscle depletion as a risk factor for development of complications.

Cancer-related malnutrition refers to adverse events caused by chemotherapy, radiotherapy and other procedures. The symptoms include nausea and vomiting, swallowing disturbance derived from a canker sore or esophagitis, and malabsorption caused by digestive mucosal damage. Such malnutrition results in patients receiving shorter-term and lower-dose chemotherapy, and this affects prognosis. In patients with colon cancer treated with 5-fluorouracil, Prado et al. found an increase in dose-limiting toxicity in patients with low muscle mass (24). Thus, a decline of muscle mass is associated with worse results in patients receiving chemotherapy (25). In the current study, there was a significant difference in the length of chemotherapy periods between the high and low PMI groups. It is likely that an increased muscle mass reduces the potential for adverse events, and assessment of PMI status might help identify patients at high risk of postchemotherapy adverse events. In this study, a negative rate of change in PMI was associated with a poor prognosis. This suggests that prevention of a negative change in muscle volume can improve the prognosis. However, this result is too preliminary to draw the conclusion that muscle training may improve the prognosis of patients with stage 4 cancer.

All the above results point to the importance of muscle mass independently of weight or BMI. Indeed, BMI has clear limitations. An overweight status or obesity with sarcopenia has been associated with decreased survival (7), although these conditions may be associated with better survival in patients with weight-losing cardiac failure (26), which seems to contradict the recent reports in patients with cancer. Adipose tissue synthesizes and secretes hormones that act as inflammatory mediators (27), and muscle depletion and treatment toxicity may be linked by systemic inflammation (28). Therefore, prospective studies are required to investigate maintenance of muscle volume and inhibition of inflammation in cancer patients. Such studies should include groups of patients in which inflammation is and is not controllable, since inflammation is involved in advanced cancer.

In conclusion, PMI calculated from preoperative CT images is a nutritional index that can serve as a prognostic factor in patients with stage 4 colon cancer. Assessment of PMI status might allow identification of patients at high risk of post-chemotherapy adverse events.

\section{Funding}

Institutional sources only.

\section{Declaration of Interest}

None of the Authors have any conflict of interest with regard to the work described here.

\section{References}

1 Hamaguchi T and Miki C: Metabolic alterations and nutritional therapy in cancer patients. J Jpn Soc Parenteral Enteral Nutr 30: 911-916, 2015.

2 Mori N, Higashiguchi T, Ito A, Futamura A, Watanabe T and Ishikawa A : Clinical significance of the cross-sectional area of the psoas major muscle on a computed tomography image in cancer patients. J Jpn Soc Parenteral Enteral Nutr 29: 1211-1217, 2014. 
3 Fukuda Y, Yamamoto K, Nishikawa K, Hirao M, Maeda S, Uemura M, Miyake M, Hama N, Oomiya H, Miyamoto A, Miyazaki M, Ikeda M, Takami K Nakamori S and Sekimoto M: The impact of postoperative complication of sarcopenia in gastrointestinal cancer patients. Jpn J Surg Metab Nutr 50: 1320, 2016.

4 Kataoka M, Yoshioka S, Shiobara M, Wakatsuki K, Suda K, Miyazawa K Miyoshi T and Ooeda Y: Influence of fatty liver development and recurrence of primary disease on nutritional status after pancreaticoduodenectomy. J Jpn Surg Assoc 76: 671676, 2015

5 Prado CM, Baracos VE, McCargar LJ, Reiman T, Mourtzakis M, Tonkin K, Mackey JR, Koski S, Pituskin E and Sawyer MB: Sarcopenia as a determinant of chemotherapy toxicity and time to tumor progression in metastatic breast cancer patients receiving capecitabine treatment. Clin Cancer Res 15: 29202926, 2009.

6 van Vledder MG, Levolger S, Ayez N, Verhoef C, Tran TC and Ijzermans JN: Body composition and outcome in patients undergoing resection of colorectal liver metastases. Br J Surg 99: 550-557, 2012.

7 Otsuji H, Yokoyama Y, Ebata T, Igami T, Sugawara G, Mizuno $\mathrm{T}$ and Nagino M: Preoperative sarcopenia negatively impacts postoperative outcomes following major hepatectomy with extrahepatic bile duct resection. World J Surg 39: 1494-1500, 2015.

8 Ignacio de Ulíbarri J, González-Madroño A, de Villar NG, González P, González B, Mancha A, Rodríguez F and Fernández G: CONUT: a tool for controlling nutritional status. First validation in a hospital population. Nutr Hosp 20: 38-45, 2005.

9 Clavien PA, Barkun J, de Oliveira ML, Vauthey JN, Dindo D, Schulick RD, de Santibañes E, Pekolj J, Slankamenac K, Bassi C, Graf R, Vonlanthen R, Padbury R, Cameron JL and Makuuchi M: The Clavien-Dindo classification of surgical complications: five-year experience. Ann Surg 250: 187-196, 2009.

10 Shen W, Punyanitya M, Wang Z, Gallagher D, St-Onge MP, Albu J, Heymsfield SB and Heshka S: Total body skeletal muscle and adipose tissue volumes: estimation from a single abdominal cross-sectional image. J Appl Physiol 97: 2333-2338, 2004.

11 Mourtzakis M, Prado CM, Lieffers JR, Reiman T, McCargar LJ and Baracos VE: A practical and precise approach to quantification of body composition in cancer patients using computed tomography images acquired during routine care. Appl Physiol Nutr Metab 33: 997-1006, 2008.

12 Baumgartner RN, Koehler KM, Gallagher D, Romero L, Heymsfield SB, Ross RR, Garry PJ and Lindeman RD: Epidemiology of sarcopenia among the elderly in New Mexico. Am J Epidemiol 147: 755-763, 1998.

13 Gray BN: Colorectal cancer: the natural history of disseminated disease: a review. Aust N Z J Surg 50: 643-646, 1980.

14 Wood CB, Gillis CR and Blumgart LH: A retrospective study of the natural history of patients with liver metastases from colorectal cancer. Clin Oncol 2: 285-288, 1976.

15 Watanabe T, Itabashi M, Shimada Y, Tanaka S, Ito Y, Ajioka Y, Hamaguchi $\mathrm{T}$, Hyodo I, Igarashi $\mathrm{M}$, Ishida $\mathrm{H}$, Ishihara $\mathrm{S}$, Ishiguro M, Kanemitsu Y, Kokudo N, Muro K, Ochiai A, Oguchi M, Ohkura Y, Saito Y, Sakai Y, Ueno H, Yoshino T, Boku N, Fujimori T, Koinuma N, Morita T, Nishimura G, Sakata Y,
Takahashi K, Tsuruta O, Yamaguchi T, Yoshida M, Yamaguchi N, Kotake K, Sugihara K; Japanese Society for Cancer of the Colon and Rectum: Japanese Society for Cancer of the Colon and Rectum (JSCCR) Guidelines 2014 for treatment of colorectal cancer. Int J Clin Oncol 20: 207-239, 2015.

16 Bozzetti F: Is enteral nutrition a primary therapy in cancer patients? Gut 35: S65-S68, 1994.

$17 \mathrm{Wu}$ J, Huang C, Xiao H, Tang Q and Cai W: Weight loss and resting energy expenditure in male patients with newly diagnosed esophageal cancer. Nutrition 29: 1310-1314, 2013.

18 Ockenga $J$ and Valentini L: Review article: anorexia and cachexia in gastrointestinal cancer. Aliment Pharmacol Ther 22: 583-594, 2005.

19 Miyamoto Y, Baba Y, Sakamoto T, Ohuchi M, Tokunaga R, Kurashige J, Hiyoshi Y, Iwagami S, Yoshida N, Yoshida M, Watanabe $\mathrm{M}$ and Baba H: Sarcopenia is a negative prognostic factor after curative resection of colorectal cancer. Ann Surg Oncol 22: 2663-2668, 2015.

20 Lieffers JR, Bathe OF, Fassbender K, Winget M and Baracos VE: Sarcopenia is associated with postoperative infection and delayed recovery from colorectal cancer resection surgery. Br J Cancer 107: 931-936, 2012.

21 Voron T, Tselikas L, Pietrasz D, Pigneur F, Laurent A, Compagnon P, Salloum C, Luciani and Azoulay D: Sarcopenia impacts on short- and long-term results of hepatectomy for hepatocellular carcinoma. Ann Surg 261: 1173-1183, 2015.

22 Joglekar S, Asghar A, Mott SL, Johnson BE, Button AM, Clark $\mathrm{E}$ and Mezhir JJ: Sarcopenia is an independent predictor of complications following pancreatectomy for adenocarcinoma. J Surg Oncol 111: 771-775, 2015.

23 Laurent C, Sa Cunha A, Couderc P, Rullier E and Saric J: Influence of postoperative morbidity on long-term survival following liver resection for colorectal metastases. Br J Surg 90: 1131-1136, 2003.

24 Prado CMM, Baracos VE, McCargar LJ, Mourtzakis M, Mulder KE, Reiman T, Butts CA, Scarfe AG and Sawyer MB: Body composition as an independent determinant of 5-fluorouracilbased chemotherapy toxicity. Clin Cancer Res 13: 3264-3268, 2007.

25 Antoun S, Birdsell L, Sawyer MB, Venner P, Escudier B and Baracos VE: Association of skeletal muscle wasting with treatment with sorafenib in patients with advanced renal cell carcinoma: results from a placebo-controlled study. J Clin Oncol 28: 1054-1060, 2010.

26 Oreopoulos A, Padwal R, Kalantar-Zadeh K, Fonarow GC, Norris CM and McAlister FA: Body mass index and mortality in heart failure: a meta-analysis. Am Heart J 156: 13-22, 2008.

27 Shoelson SE, Herrero L and Naaz A: Obesity, inflammation, and insulin resistance. Gastroenterology 132: 2169-2180, 2007.

28 Alexandre J, Goss-Goupil M, Falissard B, Nguyen ML, Gornet JM, Misset JL and Goldwasser F: Evaluation of the nutritional and inflammatory status in cancer patients for the risk assessment of severe haematological toxicity following chemotherapy. Ann Oncol 14: 36-41, 2003.

Received September 7, 2016

Revised September 20, 2016

Accepted September 28, 2016 